\title{
O ESTADO DEMOCRÁTICO DE DIREITO DE 1988 E SUA (IN) COMPATIBILIDADE COM O NEOLIBERALISMO
}

\section{THE DEMOCRATIC STATE OF LAW OF 1988 AND ITS (IN) COMPATIBILITY WITH NEOLIBERALISM}

\section{Daniel Júnior Rodrigues Alvarenga}

Acadêmico do $7^{\circ}$ período do curso de Direito do Centro Universitário Doctum de Teófilo Otoni e Presidente do Diretório Acadêmico do curso de direito Rosemiro Pereira Leal, Centro Universitário Doctum de Teófilo Otoni (UniDoctum), Brasil

E-mail: danieljunior2408@outlook.com

Hazel Ena Socorro Santos Graduada e mestre em Direito pela Pontifícia Universidade Católica de Minas Gerais-PUC-MG,Professora no Centro Universitário Doctum de Teófilo OtoniUniDoctum,Brasil

E-mail: hazel.santos@bol.com.br Recebido: 01/05/2020 - Aceito: 20/05/2020

\section{Resumo}

O Estado Democrático de Direito busca erradicar as formas de desigualdade social, contribuindo para uma sociedade mais justa, livre e solidária, mas esses objetivos entram em choque com a política neoliberal deixando os direitos sociais a um segundo plano. Neste sentido o objetivo deste trabalho foi analisar as políticas neoliberais e sua contradição com o Estado Democrático de Direito vigente. Também Foi abordado o papel da justiça do trabalho para emancipação e inserção do mundo na sociedade capitalista, e sua diminuição de acesso face à classe trabalhadora desde a reforma da trabalhista promovida no governo Temer. Como resultado dessa diminuição de acesso viu se direitos sociais sendo suprimidos cada vez mais pela classe trabalhadora. A CLT desde seu surgimento passou por inúmeras mudanças para se adequar ao contexto atual, flexibilizando muitas de suas normas. Este estudo busca retratar as consequências da flexibilização trabalhista e sua relação com a política neoliberal. Utilizou-se como procedimento metodológico a pesquisa bibliográfica. 
Palavras-chave: Flexibilização; Neoliberalismo; Justiça do Trabalho.

\section{Abstract}

The Democratic Rule of Law seeks to eradicate forms of social inequality, contributing to a more just, free and solidary society, but these objectives clash with neoliberal politics leaving social rights in the background. In this sense, the objective of this work was to analyze neoliberal policies and their contradiction with the current Democratic State of Law. The role of labor justice for the emancipation and insertion of the world in capitalist society was also addressed, and its decrease in access to the working class since the labor reform promoted by the Temer government. As a result of this diminished access, social rights were increasingly being suppressed by the working class. Since its inception, CLT has undergone numerous changes to adapt to the current context, making many of its rules more flexible. This study seeks to portray the consequences of labor flexibility and its relationship with neoliberal politics. Bibliographic research was used as the methodological procedure.

Keywords: Flexibility; Neoliberalism; work justice.

\section{1-Introdução}

O presente trabalho busca fazer uma análise do Estado Democrático de Direito brasileiro e sua incompatibilidade com o modelo neoliberal. Com a crise econômica global que se iniciou em 2009 vários países buscaram solução para sair dela, de modo a atingir substancialmente as relações entre a regulação estatal dos direitos trabalhistas.

Neste contexto, surge à flexibilização das leis trabalhistas que tornam as normas trabalhistas moldáveis as diversas situações. Os empresários dizem que a rigidez da legislação trabalhista acarreta muito custo, inclusive em razão dos tributos que incidem sobre a folha salarial. Sendo assim, segundo aqueles, a sempre saída milagrosa para o desentrave da atividade econômica e a geração de empregos, seria a flexibilização da legislação trabalhista. São vários mecanismos usados para materializar essa forma de fragilização trabalhista, mas destaca-se o papel dos governos neoliberais. 
Surge, portanto, a questão problema que norteia a presente pesquisa: quais são os impactos da flexibilização trabalhista promovida pelos governos considerados neoliberais brasileiros no âmbito socioeconômico do Estado Democrático de Direito da Constituição de 1988?

Assim, o objetivo do presente trabalho foi demonstrar como foram as consequências da flexibilização trabalhista promovida pelos governos neoliberais brasileiros e seus impactos socioeconômicos no atual Estado Democrático de Direito brasileiro, em especial nas classes trabalhadoras de maior vulnerabilidade social.

Utilizou-se como procedimento metodológico a pesquisa bibliográfica. Para melhor divisão do tema, este artigo possui cinco partes. O primeiro iniciase com esta introdução. O segundo buscou conceituar o que é o Estado Democrático de Direito e sua relação com o neoliberalismo. $O$ terceiro foi abordado o papel da Justiça do Trabalho no Brasil enquanto instrumento de inserção do individuo na sociedade e de distribuição de renda. O quarto uma análise dos governos neoliberais brasileiros e seus impactos na legislação trabalhista. O quinto se refere às considerações finais sobre o tema. Para melhor compreensão do tema objeto de estudo do presente trabalho, utilizou-se como procedimento metodológico a pesquisa bibliográfica.

\section{2-O Estado Democrático de Direito}

Originou-se após a Segunda Guerra Mundial decorrente de toda ebulição social que se viu pelo mundo. Tendo seus primeiros reflexos nas constituições da França (1946), Itália (1947), Alemanha (1949) e serviram de parâmetro para a formulação de Constituições por diversos países (DELGADO e DELGADO 2012).

O Estado Democrático de Direito se organiza através de um tripé estruturante: "a pessoa humana, com sua dignidade; sociedade política, concebida como democrática e includente, sociedade civil, também concebida como democracia e includente" (DELGADO e DELGADO,2012 p.42). E tendo como novo preceito a desmercantilização de alguns princípios, além de permitir 
uma intervenção estatal na economia, haja vista que a dignidade da pessoa humana, direitos individuais e fundamentais, uma sociedade livre justa e solidaria e redução das desigualdades regionais são princípios e objetivos que a iniciativa privada, por si só, não é capaz de garantir através de um modelo econômico neoliberal e incompatível com o Estado Democrático de Direito (DELGADO e DELGADO,2012).

Este modelo de Estado foi recebido pela Constituição de 1988 no Brasil, onde elevou os ramos jurídicos sociais, sobretudo o Direito do Trabalho (DEGADO E DELGADO,2012).

\begin{abstract}
Na verdade, no paradigma do Estado Democrático de Direito ganha especial ênfase o valor trabalho, compreendido como instrumento decisivo para a realização do projeto constitucional de afirmação da dignidade da pessoa humana, democratização da sociedade política e da sociedade civil e alcance da justiça social- o que transforma os princípios e regras do Direito do Trabalho em parte integrante do núcleo principal da Constituição da República(DELGADO e DELGADO,2012.p.9)
\end{abstract}

A atual Constituição da República se pauta na formação de um estado democrático de direito que tem como pilar o direito fundamental ao trabalho digno (DELGADO e DELGADO, 2012)

\begin{abstract}
O Direito do Trabalho contemporâneo, desde a Constituição de 1988, deve ser interpretado a partir de dois eixos temáticos de sustentação: os direitos fundamentais da pessoa humana e o paradigma do Estado Democrático de Direito. É que a concretização das premissas teleológicas básicas do Direito Trabalho depende, necessariamente, da articulação dos direitos fundamentais nas relações de trabalho, premissa essencial á conformação efetiva do conceito magno de Estado Democrático de Direito (DELGADO E DELGADO,2012.p9)
\end{abstract}

Neste cenário, o Direito do Trabalho exerce uma importante função, na medida em que insere o homem na sociedade dando a ele o poder de aquisição de mercadorias, além de sua emancipação e construção social, caso não existam condições mínimas para o homem exercê-lo, o que ocasiona a perda de sua essência (DELDADO e DELGADO,2012). "Se ao trabalhador não são asseguradas condições mínimas de saúde e de segurança no trabalho, por exemplo, não há espaço para o exercício do direito fundamental ao trabalho digno, que será mera abstração" (DELGADO e DELGADO,2012,p.61). O Direito 
do Trabalho prevê condições mínimas que assegurem a dignidade do trabalhador, haja vista que o trabalho é um direito fundamental como dispõe a Constituição de 1988.

O Direito do trabalho é um mecanismo que mais consegue uma reciprocidade diante do sistema capitalista, promovendo uma distribuição de renda e inserção na sociedade.

\begin{abstract}
Nesse quadro, o ramo justrabalhista, com seu caráter e seu objetivo de distribuição de renda e de poder, além do importante caráter e objetivo de pacificação social, é mecanismo notável de preservação do próprio sistema capitalista, assim como da sociedade democrática (DELGADO e DELGADO,2012, p110).
\end{abstract}

A Constituição de 1988 serviu como prisma para além de garantir o direito ao trabalho digno ajudou a criar e estruturar a Justiça do Trabalho servindo como ferramenta de justiça social (DELGADO e DELGADO,2012).

Portanto, a Constituição de 1988 também fortalece o sentido axiológico atribuído a Justiça do Trabalho, fundado e ancorado no valor da justiça social, e que deve vincula a interpretação e aplicação do Direito, no marco do Estado Democrático de Direito. Ou seja, a Justiça do Trabalho é considerada um dos mais sólidos e democráticos instrumentos jurídicos e institucionais para a concretização da dignidade do ser humano e dos direitos fundamentais nos conflitos de interesses do mundo do trabalho (DELGADO e DELGADO, 2012.p148).

\title{
3-O Papel da Justiça do Trabalho no Brasil
}

A partir das décadas de 1930 e 1940 a Justiça do Trabalho no Brasil começou a se expandir ajudando na desmercantilização da força de trabalho (DELGADO e DELGADO, 2012). Mas, o processo de desmercantilização do trabalho feito por meio do modelo de normatização autônoma e privatística respeitando a atuação sindical, dando a eles notoriedade e prerrogativas na ordem jurídica, tais prerrogativas aos sindicatos auxiliam na desmercantilização do trabalho (DELGADO e DELGADO,2012).

Com o advento, entretanto, da hegemonia neoliberal no Ocidente, desde finais dos anos de 1970, o modelo negociado clássico perdeu parte importante de sua eficiência desmercantilizdora, em face dos significativos assédios e restrições direcionados aos sindicatos desde então nos países matrizes desse modelo, com destaque para a Inglaterra e os EUA (DELGADO e DELGADO, 2012 p.152) 
Diante desse contexto de desmercantilização, DELGADO e DELGADO diz que:

Com a nova Constituição, portanto, o sistema trabalhista brasileiro de desmercantilização do trabalho ganhou três novos pilares, além dos três oriundos das décadas oriundos das décadas precedentes: um sistema sindical com maior liberdade de organização e atuação(embora os sindicatos passem por crise inegável nesse período, parcialmente provocada pela inadequação das regras legais de sua estruturação ainda vigentes); uma dinâmica de negociação coletiva mais generalizada do que em qualquer época no passado; o destaque alcançado pelo Ministério Púbico do Trabalho, dotada de novo perfil após 1988(DELGADO e DELGADO,2012.p155).

A reforma trabalhista de 2017 comprometeu diversos princípios do Direito do Trabalho como, por exemplo: o princípio da primazia da realidade, o princípio da razoabilidade e o princípio da boa-fé, o princípio da proteção, o princípio da irrenunciabilidade e o princípio da continuidade. (SILVA e SILVA, 2019).

O princípio da proteção está relacionado ao empregado uma vez que este é o elo mais fraco na relação jurídico trabalhista. O princípio da irrenunciabilidade do direito ampara o empregado e os seus diretos, servindo como proteção para que o trabalhador hipossuficiente não venha abrir mão dos mesmos em benefício do empregador. A continuidade da relação de emprego traduz a ideia que em nosso ordenamento jurídico, em regra, os contratos de trabalho são estabelecidos por tempo indeterminado, mas possui exceções. $O$ princípio da primazia da realidade sobre a forma ensina que, o que ocorre de fato no contexto de trabalho tem mais relevância do que o que este estabelecido no contrato. O princípio da razoabilidade tem por objetivo afastar aquilo que ultrapassa as razões humanas na relação de trabalho. O princípio da boa-fé estabelece que deva a existir na relação trabalhista uma relação ética entre as partes, neste sentido Américo Plá Rodrigues diz que:

Conduta da pessoa que considera cumprir realmente com o seu dever. Pressupõe uma posição de honestidade e honradez no comércio jurídico, porquanto contém implícita a plena consciência de não enganar, não prejudicar, nem causar danos. Mais ainda: implica a convicção de que as transações são cumpridas normalmente, sem trapaças, sem abusos nem desvirtuamentos. (2000, p. 425) 
A reforma trabalhista trouxe inúmeras mudanças na vida do empregado como na do empregador, deixando o empregado em desvantagem em relação ao empregador. Deste modo, possibilitou a flexibilização, como, para citar alguns exemplos: redução da jornada de trabalho como da remuneração, alargou a possibilidade de acordar a jornada de trabalho e estabelecer salários diretamente através de acordo individual entre empregado e empregador sem a presença obrigatória do sindicato obreiro (é o que ocorre com o dispositivo do artigo 59, da CLT), a figura do autônomo contínuo exclusivo, o trabalho intermitente. Além disso, fragilizou a força sindical, pois proporciona as empresas que possui mais de 200 funcionários a constituição de uma comissão para os representá-los frente ao patrão, não exigindo mais a participação dos sindicatos, a não obrigatoriedade da presença do sindicato nas rescisões contratuais, a terceirização seja na atividade meio ou fim dentre outros.

Inicialmente o objetivo da reforma era aumentar emprego e modernizar as relações de trabalho. Diante disso Maurício Godinho Delgado e Gabriela Neves Delgado, diz que:

\begin{abstract}
A reforma trabalhista implementada no Brasil por meio da Lei n. 13.467, de 13 de julho de 2017, desponta por seu direcionamento claro em busca do retorno ao antigo papel do Direito na História como instrumento de exclusão, segregação e sedimentação da desigualdade entre as pessoas humanas e grupos sociais (2017, p. 39-40).
\end{abstract}

A reforma trabalhista vai contra os princípios sociais da Constituição Federal e flexibilizando e desregulamentando normas essenciais aos contratos de trabalho. Conforme Mauricio Godinho Delgado e Gabriela Neves Delgado : "a Lei n. 13.467/2017 tenta instituir múltiplos mecanismos em direção gravemente contrária e regressiva à concepção de Estado Democrático de Direito (2017, p. 40)".

O desrespeito provocado pela flexibilização às normas trabalhistas contidas na CLT é de grande impacto no contexto socioeconômico no qual está inserido o trabalhador. Neste sentido, Mauricio Godinho Delgado (2017, p. 41) diz que "o Direito do Trabalho realiza um importante papel de política pública de distribuição de renda no mundo da economia e da sociedade capitalista, no entanto, a Lei n. 13.467/2017 busca romper com essa lógica(2017, p. 41)”. 
$\mathrm{Na}$ verdade, os princípios constitucionais da centralidade da pessoa humana na vida real do Direito do Trabalho, da dignidade da pessoa humana, da valorização do trabalho e do emprego, do bem-estar individual e social, da igualdade em sentido material e da subordinação da propriedade privada à sua função socioambiental são repetidamente negligenciados ou diretamente afrontados por diversas regras jurídicas da na nova Lei (DELGADO,2017,p.41).

Aponta-se que a reforma trabalhista fere diversos princípios do Direito do Trabalho, e fragilizam as relações do empregado com o empregador. Uma dessas consequências foi à restrição do acesso do trabalhador à Justiça do Trabalho, nesse sentido:

\begin{abstract}
A tentativa de emasculação [sic] do Poder Judiciário Trabalhista por intermédio de preceitos da Lei n. 13.467/2017, por exemplo o art. 8., $\S \S 2$. e 3., e o art. 702, I, "f" e §§ 3. e 4., ambos da CLT. Os novos dispositivos legais, se não bastassem outras afrontas, agridem, manifestamente, somo se vê, o princípio constitucional da separação dos poderes (art. 2., CF), e o princípio e garantia de independência do judiciário (art. 2., CF), além das próprias estrutura e lógica de atuação do Poder Judiciário (art. 92, caput e incisos II-A e IV, CF) (DELGADO,2017.p 47).
\end{abstract}

O enfraquecimento ao acesso à Justiça do Trabalho enfraquece muito a consolidação de direitos sociais previstos na Constituição de 1988.

Quanto à atuação dos sindicatos, um dos instrumentos que sempre ajudou na efetivação dos direitos dos trabalhadores, teve seu poder de atuação drasticamente reduzido pela reforma. Em consonância, Maurício Godinho Delgado expressa que: "O novo diploma jurídico instiga o sindicalismo a se tornar potencial adversário dos trabalhadores, podendo suprimir ou atenuar, por meio da negociação coletiva trabalhista, largo número de direitos imperativamente fixados na ordem jurídica heterônoma estatal” (2017, p. 46).

A Lei da Reforma Trabalhista, entretanto, apresenta regramento distinto, vislumbrando no Direito Coletivo um instrumento adicional de regressão no patamar civilizatório mínimo assegurado pelo Direito Individual do Trabalho na ordem jurídica do país. Ao invés de ser instrumento de harmonização, agregação e, em certas situações, de adequação em face do patamar civilizatório mínimo fixado no Direito Individual do Trabalho, o Direito Coletivo do Trabalho passaria a se direcionar, nos termos da nova lei, para o caminho de se tornar mais um meio de redução do patamar civilizatório mínimo trabalhista garantido pela ordem jurídica especializada da Republica brasileira (DELGADO,2017. p 45). 
A reforma trabalhista, considerada por alguns como deforma trabalhista ainda está começando a mostrar suas consequências, servindo como instrumento para a implementação do projeto de exploração conhecido como uberização do trabalho, não havendo a tão prometida geração de emprego e nem o esperado aumento econômico como previsto pelo governo da época de sua aprovação; ao contrário, a economia declinou e, consequentemente, houve o aumento do desemprego seguido de precarização da mão de obra.

\section{4-Análise dos Governos neoliberais brasileiros de Fernando Collor de Mello, Fernando Henrique Cardoso (FHC), Michel Temer e Jair Messias Bolsonaro e suas implicações no mundo trabalhista brasileiro}

Collor fez a sua campanha eleitoral pautada em um discurso neoliberal, e se colocando como caçador de "marajás", onde dizia que acabaria com cargos públicos fantasmas tendo uma campanha muito forte contra os gastos públicos, de modo que foi uma campanha muito mais voltada à iniciativa privada. Após sua vitória, começou a implementar o neoliberalismo no Brasil por meio de algumas privatizações, porém ele não conseguiu consolidar o neoliberalismo no país devido ao seu impeachment. Um dos seus atos foi um decreto que instituiu uma Comissão de Modernização da Legislação do Trabalho, alegando que a CLT estava ultrapassada e que precisaria se adequar à nova realidade, onde os direitos individuais do trabalho passassem a ser um conjunto de normas dispositivas resultando em um prevalecimento do produto da negociação coletiva sobrepondo os direitos individuais garantidos pela lei, utilizado nas hipóteses que não é exercida a autonomia privada coletiva.

Com o fim do governo Collor, o projeto neoliberal é enterrado. Porém, com a chegada de FHC (1995 a 2003) ao poder, esse projeto ressurge, sendo implementado e consolidado. FHC disse que iria "virar a página do getulismo", da história do Brasil, ou seja, estava bem claro que o estado protetor que garantisse direitos sociais era um empecilho ao seu governo. Foi iniciada uma onda de privatizações pelo país, precarização e desregulamentação das relações de trabalho ao passo que a economia brasileira começou entrar em declínio que só sairia no governo Lula.

Duas medidas legais merecem destaque nos governos $\mathrm{FHC}$ que foram a nova reorganização ao contrato de estágio pela Lei de nำ6.494, de 1997 
incluindo o estudante do ensino médio fazendo com que o estudante perdesse a vital relação com a formação acadêmico-profissional, transformando assim, o estágio em um tipo de contrato de servidão voluntária (DELGADO,2006).E a Lei no9.601 de 1998 que previa uma contratação frágil , que em relação ao tempo que era no máximo de dois anos com reiterações em curto lapso temporal dentre esse período e quer quanto aos direitos laborativas impondo limitações a tradicionais direitos regulamentados pela CLT (DELGADO,2006). Diante disso, Rozinaldo Miani diz que: "De modo geral, a disposição do governo FHC de promover a precarização das relações de trabalho, em sintonia com os pressupostos neoliberais, ficou muito bem caracterizada com a proposição do contrato por prazo determinado" (MIANI, 2005, p.352).

Essa medida legal causou grande revolta entre os líderes sindicais surgindo várias caricaturas criticando o contrato temporário, $\mathrm{FHC}$ em resposta disse que o contrato de trabalho temporário aumentaria os empregos no Brasil visto que o país enfrentava uma grande crise de desempregos haja vista, que nos anos de1997 a 1998 a taxa de desemprego saltou de 7,8\% para 9,0\%. A teoria propunha que o contrato temporário previa a diminuição com os custos com a contratação de trabalhadores fazendo assim os empregadores contratarem mais. Segundo Miani:

De acordo com as determinações da Lei $n^{\circ}$ 9.601/98, os trabalhadores contratados sob o regime de "contrato por prazo determinado" tiveram uma redução no depósito do FGTS da ordem de $75 \%$, passando de $8 \%$ para $2 \%$; o fim do pagamento do aviso prévio; o fim da indenização de $40 \%$ do FGTS por ocasião da dispensa; a instituição da compensação das horas extras, sem o seu devido pagamento em dinheiro, através da criação de um "banco de horas"; a limitação da garantia de estabilidade para a gestante, o acidentado no trabalho, o cipeiro e o representante sindical, que valeria somente enquanto durasse o contrato; redução da contribuição ao seguro acidente de trabalho em $50 \%$, resultando numa "desresponsabilização" por parte dos patrões em relação ao investimento em segurança no ambiente de trabalho; entre outros. Outras condições de precarização também derivam desse modelo de contrato como a perda, por parte do trabalhador, do direito ao seguro desemprego (MIANI, 2005, p.352).

O governo promoveu grandes retiradas de investimentos em áreas sociais, promovendo um ambiente de austeridade econômica e social. A 
legislação sobre o contrato de trabalho temporário e permitiu que os empresários ferissem a legislação trabalhista sem sofrer nenhuma espécie de correção por parte do Estado. De acordo com Armando Boito Jr:

[...] num país periférico como o Brasil, em que capitalistas gozam de amplo poder de desrespeitar as leis, houve a percepção dos governos neoliberais de que era possível avançar na desregulamentação prática do mercado de trabalho, sem arcar com os custos políticos de alterações legais. Uma forma importante que os governos neoliberais encontraram para avançar na desregulamentação do mercado de trabalho foi tolerar e até estimular a desregulamentação ilegal, e muitas vezes oculta, praticada pelos capitalistas. $\mathrm{Na}$ década de 1990, os governos neoliberais estimularam os empregadores a contratar trabalhadores sem carteira de trabalho assinada, ao permitirem a piora da historicamente precária fiscalização das Delegacias Regionais do Trabalho e ao estigmatizarem os direitos sociais e a legislação trabalhista. O presidente Fernando Henrique Cardoso chegou a aconselhar publicamente os industriais de São Paulo a desrespeitarem as normas protetoras do trabalho, fazendo declaração pública de apoio a um acordo do Sindicato dos Metalúrgicos de São Paulo com uma empresa de sua base, no qual ficava estabelecido um contrato de trabalho por tempo determinado. Tal acordo foi invalidado pela Justiça do Trabalho. Foi o fracasso, nesse caso, da via ilegal que levou o governo FHC a elaborar o projeto de lei estabelecendo o contrato de trabalho por tempo determinado, uma de suas iniciativas mais importantes na desregulamentação das relações de trabalho (BOITO JR., 1997, p.93-94).

O contrato de trabalho temporário serviu como uma benfeitoria para os empresários, pois precarizou as relações trabalhistas e suspendeu direitos dos trabalhadores. Ao mesmo passo que fere diretamente a organização política dos sindicatos dos trabalhadores, neste sentido Miani diz que:

Com o contrato de trabalho temporário, os trabalhadores de um mesmo setor estiveram divididos e classificados em duas categorias distintas, sendo o de "primeira categoria" aquele trabalhador contratado por prazo indeterminado (contrato normal) e o de "segunda categoria" aquele contratado sob o regime de contrato temporário (MIANI, 2005, p.354).

Rozinaldo Miani diz que o contrato de trabalho temporário em tese foi:

[...] a diminuição ou a completa eliminação de alguns direitos trabalhistas para os trabalhadores e a diminuição das despesas com encargos sociais e a isenção de alguns impostos e multas para os patrões, bem como a correspondente consequência na organização política dos trabalhadores, caracterizaram o contrato de trabalho temporário. A institucionalização do subemprego, pelo incentivo a uma rotatividade perversa de mão-de-obra e pela diminuição ou eliminação de direitos 
históricos dos trabalhadores, proporcionada pelo contrato de trabalho temporário, foi a principal consequência desse processo (MIANI, 2005, p.356).

A era neoliberal de $\mathrm{FHC}$ só terminou com a eleição do Lula que conseguiu elevar o Brasil a sexta, potência mundial através de uma política econômica, no campo social, de geração de milhões de empregos formais e valorização do salário mínimo. Mas, em 2016 com a destituição da presidenta Dilma Rousseff, Michel Temer assume o governo, meses após assumir, Temer encaminhou ao congresso um projeto de lei para modificar a CLT e a Lei 6.019/74. A reforma trabalhista proporcionada pelo governo Temer foi um instrumento de concretização do neoliberalismo no Brasil, pois para os neoliberais a desnormatização das proteções do direito do trabalhador é uma diretriz econômica fundamental, pautada na competitividade e na produtividade (TEODORO, 2018).

Um dos pontos fundamentais da reforma trabalhista é a possibilidade de negociação entre os trabalhadores e empregadores através do "acordado sobre o legislado" (TEODORO,2018). Essa reforma trabalhista possui vários aspectos que refletem o receituário neoliberal. Nesse diapasão, passou a permitir, sem a presença do sindicato obreiro, as demissões coletivas, o que era proibido pela Justiça do trabalho a partir de uma interpretação dos princípios constitucionais do trabalho. Outra alteração que trouxe a reforma é a possibilidade de redução do intervalo de descanso para o almoço que antes era de uma hora, no mínimo, salvo a exceção do art.71,§ 3으. CLT). Todavia, com a reforma trabalhista de 2017, poderá ser de trinta minutos na hipótese de acordo coletivo para jornadas com mais de seis horas de duração (TEODORO,2018).

Em relação ao banco de horas que é a quantidade de horas extras trabalhadas em um dia e que seria compensada em outro dia, antes da reforma somente poderia ser estabelecido em negociação coletiva, de modo que, as horas extras precisam ser compensadas em até um ano, passado prazo, elas deveriam ser pagas em dinheiro com acréscimo de $50 \%$. Atualmente o prazo para o banco de horas ser zerado, com as horas compensadas, é menor, ele 
deve acontecer em até seis meses, mas tem a possibilidade de que o banco de horas seja realizado por acordos individuais(TEODORO,2018).

No que tange aos sindicatos, a reforma instituiu que a contribuição não será mais obrigatória, passará a ser descontada com autorização do trabalhador aumentando o poder de barganha do empresário e fragilizando os instrumentos de luta e organização política dos trabalhadores (TEODORO, 2018).

A reforma trabalhista flexibilizou muito as relações de trabalho se destacando o homme-office que é o trabalho em casa com a premissa que a pessoa quando trabalha em casa tendo maior possibilidade de fazer seu horário de trabalho, o trabalho intermitente autoriza que o trabalhador seja pago apenas pelas horas de serviço de fato efetuadas e a terceirização precarizando ainda mais as relações de trabalho (TEODORO, 2018).

A terceirização legitimada pela Lei № 13.429/2017, também foi um dos destaques no ataque a classe trabalhadora promovida por Temer. Além, de que a terceirização afronta um dos fundamentos do Estado Democrático de Direito, que é o valor social do trabalho (art.1, IV, CRFB 1988) ao passo que não respeita a dignidade do trabalhador tratando-o como se fossem mercadorias. Nesse sentido conforme DELGADO e DELGADO: "A Declaração de Filadélfia, de 1944, arrola os princípios fundamentais do Direito Internacional do Trabalho. $O$ primeiro de seus princípios afirma que o trabalho não é uma mercadoria" (DELGADO e DELGADO,2012, p .182).

As consequências da reforma proposta por Temer deixaram inúmeras consequências, dentre elas, o número de ações trabalhistas, comparando aos 12 meses antes da promulgação da reforma que foram dos meses de novembro de 2016 a outubro de 2017 e os dos meses de outubro de 2018 a setembro de 2019, caíram em 31,8\%. Temer defendeu que um dos motivos para a reforma que com ela proporcionaria um aumento de emprego no país sendo que no terceiro trimestre de 2017 a taxa de desemprego era de 12,4\%, e também houve um grande aumento de trabalho informal no mercado uma vez que no terceiro trimestre de 2016 chegou a 38,8\%e no mesmo período em 2017 chegou á $40,5 \% \%$, enquanto no terceiro trimestre de 2019 ,chegou em $41,4 \%$, esse cenário e consequência das políticas neoliberais que destrói o Estado, promovendo a 
retrocesso da sociedade salarial aumentando as ocupações não assalariadas cada vez mais precarizadas sem políticas públicas de proteção de cunho social e trabalhista. A aplicação da agenda neoliberal da reforma trabalhista diminuiu a taxa de sindicalização uma vez que dos 92,3 milhões de pessoas ocupadas em 2018 no país, 11,5 milhões estavam associadas a sindicatos. A taxa de sindicalização ficou em $12,5 \%, R$ 2,04 bilhões foi o valor total de arrecadação sindical em 2017, segundo dados da Secretaria Especial de Previdência e Trabalho do Ministério da Economia $\mathrm{R} \$ 283$ milhões foi o valor total de arrecadação sindical em 2018, segundo dados da Secretaria Especial de Previdência e Trabalho do Ministério da Economia, 86,1\% foi o tamanho da queda na arrecadação sindical em 2018, quando verificada com 2017. A fórmula neoliberal congela os empregos com exigência na escolaridade universitária desde 2015, com a ineficiência e desemprego especialmente nas famílias de classe média. Desconstruindo o mito do investimento em capital humano como solução da decadência nacional.

O governo Temer foi um dos governos que mais flexibilizou e desregulamentou o mundo do trabalho brasileiro, infelizmente essa política continuou com o governo de Bolsonaro. Com a Medida Provisória (MP) 881/2019, que flexibiliza regras trabalhistas, por exemplo, registro de ponto e a supressão de alvará para atividades de baixo risco. Conforme o governo a sanção da MP pode gerar, em dez anos, a geração de 3,7 milhões de empregos e até $7 \%$ de crescimento do Produto Interno Bruto (PIB). Inicialmente a MP previa trabalho aos domingos, mas, foi vetada. Logo após, essa MP, Bolsonaro apresentou a MP 905, que ficou conhecida como "MP verde amarela". Essa medida prevê a isenção tributária para empresas, redução de impostos ao empregador e ainda a taxação para o trabalhador que visa retirar o segurodesemprego. Além disso, o governo Bolsonaro extinguiu mais de 27 mil cargos públicos, enquanto no período de 1990 a 2002 foram extintos os empregos na base administrativa, atualmente são os intermediários.

A política adotada por Bolsonaro visa ainda mais aprofundar 0 neoliberalismo no país, o neoliberalismo não resultou somente no recuo econômico e social, a dívida pública saltou de 51,5\% em 2014, saltou para quase 79\% do PIB em 2019. O governo Bolsonaro retira direitos sociais e trabalhistas 
e diminuiu ainda mais as despesas para a contratação de trabalhadores, corroborando ainda mais com o desemprego. Com o aumento da desigualdade nutrida pela política neoliberal das políticas públicas, faz com que o Brasil seja um dos países mais desiguais do mundo. A retirada do Estado da economia para o aumento do investimento privado e desregulamentar o trabalho para aumentar ocupação profissional é um mito,visto que, desde 2010 a queda na produtividade.No Brasil, regido por Bolsonaro a produtividade do país reduziu a $0,7 \%$.

Essa política neoliberal adotada impacta diretamente a vida do trabalhador em seu dia a dia, no que tange a alimentação o brasileiro trocou o consumo da carne pelo de ovos. Em 2019, por essa razão, cada vez mais o brasileiro consome em média, 212 ovos, sendo quase o dobro do consumo em 1999.

Um dos elementos essenciais de mutação da conjuntura social brasileira é o aumento das políticas de recessão econômica, após o momento de regressão na economia nacional visto no início de 1980 e de 1990, com o encolhimento da produção no país houve um grande aumento de pobreza e desemprego entre a população (POCHAMANN e MORAES, 2017).

O governo Bolsonaro vem consolidando um projeto de desmanche total em prol dos interesses privados da burguesia, por meio das instituições do legislativo, executivo e judiciário elas não são instituições neutras, pois, eles vão funcionar a favor da população e dos seus interesses reais ou vão representar outros interesses tentando ludibridiar a população que os interesses dos bancários, empresários e a burguesia, em geral, que os interesses deles correspondem com os da população. Fazendo assim, a propagação do desmonte das políticas trabalhistas brasileiras. A política neoliberal brasileira faz com que os brasileiros trabalhem em condições que não conseguem sustentar a dignidade humana.

\section{5-Considerações Finais}

Conforme o exposto percebe-se que as políticas de cunho neoliberal não condizem com o nosso atual Estado Democrático de Direito, ferindo princípios do Direito do Trabalho como também constitucionais. Fragilizando o acesso à 
justiça pela parte da classe trabalhadora afeta a vida social dos mesmos diminuindo seu poder de compra e impactando a economia.

O trabalho cada vez mais está passando por profundas mudanças restando ao legislador criar formas de proteção trabalhista. A justiça do trabalho desempenha um papel vital na máquina do capital, permitindo que a classe trabalhadora tenha proteção e garantia de seus direitos e consequentemente a sua fragilização ao longo de governos neoliberais.

O neoliberalismo no Brasil se consolidou de diversas formas como a romantização do trabalho precário a um discurso travestido de modernização da legislação trabalhista, ou seja, a política neoliberal esteve presente em vários momentos desde a redemocratização do Brasil. Desde os anos 90 o Direito do Trabalho vem sendo atacado e fragilizado, as relações de emprego cada vez mais instáveis, as relações de trabalho como temos hoje podem seriamente a sofrer mudanças drásticas, originando uma nova classe de trabalhadores digitais. O Direito do Trabalho corre sério risco de extinção, pois cada vez mais os legisladores estão precarizando o trabalhando e beneficiando a classe dos patrões.

\section{Referências}

BOITO JR., Armando. Política neoliberal e sindicalismo no Brasil. São Paulo: Xamã, 1999.

BRASILEIRO bate recorde em consumo de ovos. Globo Rural. São Paulo, 15 de jan. de 2019. Disponível em

https://revistagloborural.globo.com/Noticias/Criacao/noticia/2019/01/brasileirobate-recorde-no-consumo-de-ovos.html . Acesso em 07 de jan. de 2019.

COSTA, Márcia da Silva. O sistema de relações de trabalho no Brasil: alguns traços históricos de sua precarização atual. Revista Brasileira de Ciências Sociais, São Paulo, v. 20, n.59, p.111-170, out.2005.

DELGADO, Maurício Godinho, DELGADO, Gabriela Neves. A reforma trabalhista no Brasil: com os comentários à Lei n. 13.467/2017. São Paulo: LTr, 2017.

DELGADO, Maurício Godinho. Curso de direito do trabalho. 5. ed. São Paulo: LTr, 2016.

DELGADO,MauricioGodinho;DELGADO,GabrielaNeves.Constituição da República e Direitos Fundamentais:dignidade da pessoa humana,justiça social e direito do trabalho.São Paulo:LTR,2012. 
MIANI, RozinaldoAntonio. As transformações no mundo do trabalho na década de 1990: o olhar atento da charge na imprensa do Sindicato dos Metalúrgicos do ABC paulista. Assis: Unesp/Campus Assis, 2005. Tese (Doutorado em História) Faculdade de Ciências e Letras de Assis, Universidade Estadual Paulista, Assis, 2005.

RODRIGUEZ, Américo Plá. Princípios de direito do trabalho. Trad. Wagner D. Giglio. 3. ed. São Paulo: LTr, 2000.

ROUBICEK, Marcelo. Como ficou o emprego 2 anos após a reforma trabalhista. Nexo Jornal, São Paulo, 07 de nov. de 2019. Disponível em: https://www.nexojornal.com.br/expresso/2019/11/07/Como-ficou-o-emprego-2anos-após-a-reforma-trabalhista. Acesso em 07 de jan. de 2020.

ROUBICEK, Marcelo. Como Ficou o quadro de ações trabalhistas 2 anos após a reforma. Nexo Jornal, São Paulo,03 de nov. de 2019. Disponível em : https://www.nexojornal.com.br/expresso/2019/11/03/Como-ficou-o-quadro-deações-trabalhistas-2-anos-após-a-reforma . Acesso em 07 de jan. de 2020. ROUBIECK, Marcelo. Acordo Coletivo: como ficou após 2 anos da reforma trabalhista. Nexo Jornal, São Paulo, 05 de nov. de 2019. Disponível em: https://www.nexojornal.com.br/expresso/2019/11/05/Acordo-coletivo-comoficou-2-anos-após-a-reforma-trabalhista . Acesso em 07 de jan. de 2020.

SILVA, Danilo Rubens Martins da e SILVA Giulliano Rodrigo Gonçalves e. A APLICABILIDADE DOS PRINCÍPIOS DO DIREITO DO TRABALHO APÓS A REFORMA TRABALHISTA DE 2017. Jus.com.br.2019.Disponível em:https://jus.com.br/artigos/75826/a-aplicabilidade-dos-princípios-do-direitodo-trabalho-apos-a-reforma-trabalhista-de-2017. Acesso em 01 de mar. de 2020.

TAXA de sindicalização cai para 12,5\% em 2018, e atinge menor nível em sete anos. Agência IBGE Notícias. São Paulo, 18 de dez. de 2019. Disponível em: https://agenciadenoticias.ibge.gov.br/agencia-noticias/2012-agencia-denoticias/noticias/26423-taxa-de-sindicalizacao-cai-para-12-5-em-2018-e-atingemenor-nivel-em-sete-anos . Acesso em 07 de jan. de 2020.

BOLSONARO sanciona MP da liberdade econômica, Revista Veja, São Paulo, 20 de set. de 2019. Disponível em:

https://veja.abril.com.br/economia/bolsonaro-sanciona-mp-da-liberdadeeconomical. Acesso em 07 de jan. de 2020.

TEODORO, Luiz Claudio de Almeida. A reforma trabalhista do governo temer: Inspiração neoliberal e o desmanche dos direitos sociais. Revista Serviço Social em Perspectiva, 2018, 2.Esp.: 578-590.

TOLEDO, José Roberto. Desemprego Cresceu 15\% em 98. Folha de São Paulo, São Paulo, 01 , de dez. de 1998. Disponível em: https://www1.folha.uol.com.br/fsp/dinheiro/fi0112199926.htm . Acesso em 07 de jan. de 2020. 